\title{
Cultivation Pattern for Design Talents in Vocational and Technical Colleges Under the View of Rural Vitalization
}

\author{
Hui $\mathrm{Fu}^{1, \mathrm{a}^{*}}$, Jia Mei Shou ${ }^{2, \mathrm{~b}}$, Zhi Hui Sun ${ }^{3, \mathrm{c}}$ \\ ${ }^{1}$ Department of Art and Design, Chongqing Vocational College Of Culture and Arts, Banan District, Chongqing, \\ China \\ ${ }^{2}$ Department of Art and Design, Chongqing Vocational College Of Culture and Arts, Banan District, Chongqing, \\ China \\ ${ }^{3}$ Department of Art and Design, Chongqing Vocational College Of Culture and Arts, Banan District, Chongqing, \\ China \\ a*799567636@qq.com \\ b717571053@qq.com \\ c402715883@qq.com
}

\begin{abstract}
Under the environment of implementation the strategy of rural vitalization, how to cultivate the design talents in the more practicing and effective way to serve rural vitalization for the economic and cultural development of the whole society has become the major task of design education reform and development in vocational and technical colleges. The concept of rural vitalization has posed new requirements and challenges to the cultivation pattern for design talents in vocational and technical colleges. Under such a context, it is of great necessity to define the logic corresponding relations between design talents in higher vocational colleges and rural vitalization. Efforts should also be made to optimize the professional knowledge structure for design talents and the long-tern mechanism of talents cultivation which can promote design majors in vocational and technical colleges to serve rural vitalization in terms of new teaching model, curriculum system and faculty team.
\end{abstract}

Keywords: Rural Vitalization, Design Talents in Vocational and Technical Colleges, talents cultivation

\section{乡村振兴视域下高职设计类人才培养模式研究}

\author{
付卉 $1, \mathrm{a}^{*}$ 寿家梅 $2, \mathrm{~b}$ 孙志慧 $3, \mathrm{c}$
}

1 重庆文化艺术职业学院艺术设计系, 巴南区, 重庆, 中国

2 重庆文化艺术职业学院艺术设计系, 巴南区, 重庆, 中国

3 重庆文化艺术职业学院艺术设计系, 巴南区, 重庆, 中国

a*799567636@qq.com

b717571053@qq.com

c402715883@qq.com

\section{摘要}

在国家乡村振兴战略部署背景之下，如何以更具实践性、更具有效性的方式培养设计类人才，服务乡村振兴促 进社会经济文化发展，已然成为高职设计类教育改革发展的重要任务。乡村振兴视域之下，对高职设计类人才 培养模式提出了全新的要求与挑战。厘清高职设计类人才与乡村振兴逻辑对应关系，优化设计类人才专业知识 结构, 逐步建构高职设计类专业服务乡村振兴的新型教学模式、课程体系、师资队伍等人才培养长效机制。

关键词：乡村振兴，高职设计类专业，人才培养模式 


\section{1.高职艺术设计人才服务乡村振兴的历史契 机}

2017 年党的十九大做出乡村振兴重大决策, 在此 部署之下, 乡村的全面振兴需要实现乡村产业、人才、 文化、生态的全方位振兴。基于此, 艺术设计与乡村 相关产业合作前行成为产业转型的重要推动力, 乡村 建设规划和艺术设计融合发展成为一种时代趋势, 乡 村全方位振兴更是对设计人才专业能力提出全方位 需求。

在此基础上, 进行乡村振兴视域下进行高职设计 类人才培养模式研究。以人才培养以服务美丽乡村建 设、助力乡村文旅产业升级、推动乡村经济发展为逻 辑起点, 以实现高职艺术设计专业人才资源合理配置, 优化人才就业结构, 促进设计人才服务乡村振兴全局 部署为总体目标, 进行人才培养模式的改革与实践, 逐步建立人才培养符合国家发展战略、人才输出为区 域乡村经济发展做贡献的新型高职设计类人才培模 式。

\section{2. 国内高校设计专业人才服务乡村振兴的探 索与实践}

近年来，随着乡村振兴战略的持续推进，乡村景 观规划、乡村文旅融合发展、乡村乡土资源研发利用 等诸多项目开展都离不开专业艺术设计人才为其赋 能。在此基础上, 众多艺术院校、高校艺术设计专业 就艺术设计人才服务乡村振兴的理论建构、路径方式 展开研究, 主要成果体现在以下两方面。

第一，艺术院校、高校艺术设计专业探索艺术设 计人才服务乡村振兴的道路实践。四川工商职业技术 学院艺术设计系师生成立专项设计工作室, 在都江堰 大观镇 “小满村” 开展乡村整体形象设计、特色农产 品包装设计、艺术扶贫教育、旅游文创产品设计等多 项设计工作助力乡村振兴; 浙江农林大学艺术学院师 生借助 AR、VR、互联网技术搭建交互式虚拟乡村空 间社区, 展示乡村特色文化旅游景观, 让用户全视域 体验村落的人文、历史、地理、产业格局; 湖南大学 自 2009 年着手实施 “新通道” 设计与社会创新项目, 在贫困少数民族地区、深度贫困地区再造民间美术、 非遗手工艺的视觉传播方式、重塑乡村公共环境, 以 现代设计融合至乡村规划发展中; 广州美术学院艺术 设计系师生开展乡村儿童户外游乐设施设计项目, 用 现代设计的力量改善乡村儿童的娱乐生活; 四川美术 学院艺术设计人才培养以 “绿色设计与可持续发展” 为基础, 以 “创新设计十乡村” 为主线, 以 “产品体
系化、产业链条化、产能规模化、生态多样化” 为抓 手, 持续探索艺术设计人才在乡村振兴中发挥的机制 作用。

第二, 高校艺术设计人才服务乡村振兴人才培养 模式的建构探索。张玉山论文《基于乡村振兴背景的 设计类研究生教育模式探究》, 指出国内设计类研究 生教育课程结构不合理、人才培养目标不契合社会需 求的诸多问题, 提出将设计教学项目对接乡村建设发 展, 课题研究、毕业设计融合乡村振兴战略的方案举 措; 李启淑论文《以艺术设计服务乡村振兴战略的教 学方法研究》, 以本科院校艺术设计专业对接乡村振 兴略为出发点, 在课程理念革新、教学内容改革、课 程体系建构等方面提出建议方案。

\section{3.建构服务乡村振兴高职设计类人才培养模 式的积极意义}

\section{1 在乡村振兴战略层面上, 能够为乡村文化 建设、经济发展提供持续地人才动力}

在乡村振兴战略背景下,乡村发展对艺术设计人 才需求呈井喷式诉求, 乡村文化振兴、乡村文旅融合、 乡村传统艺术挖掘再造都离不开艺术设计人才的顶 囊相助。研究乡村振兴视域下高职艺术设计人才培养 模式的重新建构, 是将艺术设计人才培养与区域乡村 经济文化发展结合的有效尝试, 是转变传统人才培养 定位, 将高职艺术设计人才输送乡村服务乡村的全新 探索, 具有重要的实践价值意义。

\section{2 在高职院校定位人才培养目标方面, 能够 将人才培养与社会现实需求紧密结合, 完善 人才培养建构机制}

现阶段, 高职设计类人才培养结构与培养目标, 是为成熟的设计市场培养设计人才, 是为城市经济发 展、城市消费产业、城市设计市场输送设计人才，存 在着与本科院校艺术设计人才培养目标同质化、人才 输送渠道同类化等诸多问题, 造成高职艺术设计专业 人才资源过剩等现实问题。将高职艺术设计人才培养 置于乡村振兴的发展战略之下, 将人才培养模式的建 构紧密连接最现实的社会需求, 研究视野跳出人才培 养的一般范式，将新兴的乡村产业、乡村文旅开发、 乡村特色文化建构纳入到人才培养的规划中来, 开拓 了更为宽广的人才培养模式研究领域。能够突破传统 高职艺术设计人才培养模式, 培养出助力乡村振兴发 展的专业人才, 培育出能够服务乡村、建设乡村的设 
计人才, 在完善人才培养机制方面, 有重要的理论建 构价值。

\section{4.高职设计类人才服务乡村振兴的逻辑分析}

乡村振兴的根本目的是：推进乡村产业、生态、 文化、生活的全方位振兴，农民物质生活精神风貌得 到全面提高，实现全民小康与全民共同富裕。在此全 局规划中，乡村产业结构的转型升级与艺术设计之间 存在天然的共生关系，乡村产业、生态、文化、生活 的改造重建都离不开现代设计为其赋能并为其注入 发展动力, 艺术设计专业人才在乡村规划、乡村公共 空间设计、乡村景观改造等诸多项目都发挥着不可替 代的作用。

厘清乡村振兴产业结构类型、乡村产业项目种类, 明确乡村规划、乡村文化传承等概念, 明确乡村振兴 与设计需求、乡村产业结构升级与设计人才的逻辑关 系, 以此作为研究高职设计类人才培养模式的起点与 分析基础。 ${ }^{[1]}$

乡村产业项目与艺术设计的共生结构可归纳为: “乡村区域非遗资源十文创衍生产品开发”, “乡村旅 游资源项目十文旅产品设计研发”, “乡村农副产品十 产品包装创意再设计” 等, 乡村规划与艺术设计的共 存状态可归纳为: “乡村整体规划十视觉 VIS 设计”, “乡村整体风貌建构十文化景观设计”, “乡村乡土建 筑改造十建筑景观设计重构” 等, 乡村文化建设与艺 术设计的共存机制可归纳为: “乡村特色文化传承十 艺术表现视觉化”, “乡村文化活态传播十艺术设计图 像化”等。

\section{5.现阶段高职设计类人才培养模式存在的问 题}

目前国内高职艺术设计人才培养机制学制常设 3 年, 课程结构包含人文素质课、拓展选修课、专业基 础课、专业核心课、专业选修课几大模块, 专业课程 板块包括校内专业技能课程、设计企业观摩实习课程、 跟岗顶岗实习课程等架构内容, 师资结构主要分为校 内专任教师、设计行业专业带头人两大板块, 教学模 式多为以学院内部教学为主体, 企业教学实践教学为 辅的一般方法, 以培养具备基础设计理论、掌握一般 设计知识、具备一定水准应用技能的设计行业从业者 为一般培养目标。[2]数年来, 高内高职设计类专业人 才培养取得了一定成效, 但随着经济文化的迅猛发展 与国家一系列战略部署的推进, 社会对设计人才结构 提出了更多维度的需求, 高职设计类人才培养模式凸 显出以下几方面问题。

\section{1 高职设计类专业教育模式缺乏创新}

在新时代, 设计教育是一项突破设计技能范畴, 涉及到诸多产业领域的综合性专业教育。我国高职艺 术设计专业虽然纳入到国家学科建设体系, 但由于受
西方传统设计教育、受本科院校设计教育模式的刚性 影响, 导致所形成的高职设计专业教育模式缺乏针对 性与创新性。长期以来设计教育未能形成差异化、个 性化的育人模式，人才培养缺乏与国家大政方针政策 对接的时效性, 造成高职设计专业育人模式未能全面 高效发挥职业教育优势的现状。

\section{2 课程结构设计单一化}

课程形式设计单一。高职设计类专业课程内容局 限在设计理论、设计基础应用、设计操作一般技能, 课程内容结构过于陈旧, 课程形式结构趋于封闭化, 课程设计相对社会需求愈发滞后。课程架构缺乏与相 关专业的融合衔接, 课程内容局限在设计专业知识讲 解, 未能将专业课程设计置于更广领域的专业群中, 课程结构规划设计未能全面将专业知识结合社会新 动向新需求, 从而造成课程内容缺乏创新, 未能有效 发挥将设计专业知识的应用效能。

\section{3 设计人才培养目标与社会需求存在脱节}

高职设计类专业培养了大量设计行业从业人员, 职业教育与本科研究生教育人才培养目标、人才培养 就业渠道存在同质化现象，从而造成高职类设计人才 就业竞争力不强, 毕业生不得转投其他行业的现实现 象。在此情形下, 培养符合乡村振兴战略需求的设计 专业人才, 实现高职设计人才就业分流势在必行。

\section{6.乡村振兴视域下高职设计类专业人才培养 路径建构方案}

\section{1 明确乡村振兴视域下高职设计类人才培养 目标}

转变高职艺术设计人才培养定位, 转变以培养单 纯设计技能、单一化知识结构、单维度向城市输送设 计人才的人才培养方式, 将设计人才培养目标与国家 战略结合起来, 将人才培养定位与乡村振兴对设计人 才的真实需求结合起来, 建构教学体系、教研科研、 产学研一体化等融合至乡村振兴轨道的长效机制。

确立能够符合国家乡村振兴战略需求、能够契合 乡村文旅融合开发需要、能够为区域乡村经济发展贡 献专业知识的新型设计人才培养目标。建构切实可行 的高职设计人才培养模式, 从而充分调动高职艺术设 计专业人才在乡村公共空间设计改造、乡村文创产品 研发设计、乡村文化品牌建设等方面的专业效能, 实 现高职艺术设计人才培养目标多维化与乡村振兴战 略部署对设计人才需求的双赢。

\section{2 建构乡村振兴背景下人才培养机制}

\subsection{1 推动高职设计类专业教学模式改革}


突破以学院内部封闭式授课为主体的教学模式, 充分对接区域乡村振兴设计项目的真实需求，推动以 改造乡村旧存村落生态为目的、承接乡村设计实战项 目为驱动、师生共建乡村设计研发课题组为导向的新 型教学模式改革。

\subsection{2 逐步推进高职设计类专业课程体系架构 革新}

打破艺术设计专业课程单一化、封闭化的建构体 系, 寻求乡村振兴与高职设计人才培养在课程建构上 的逻辑对应关系。课程架构视野迈出艺术设计本专业, 将乡村振兴所涉及的文旅政策、非遗传承、人文生态 等有关内容纳入到艺术设计类课程的建构体系, 将与 乡村振兴所契合的文化管理、商业经贸等相关专业课 程内容统筹到课程架构的规划中来。[3]

\subsection{3 探索高职设计类教师队伍的重构方式}

改变校内专业设计教师为主体的教师结构, 建构 乡村振兴背景下多元化的教师队伍结构。在乡村振兴 背景下, 设计人才需要多层次、多维度、多方位的知 识架构, 艺术设计人才的培养不仅需要专业类设计教 师传授专业知识, 更需要多元化知识结构的师资队伍 为人才培养注入新鲜血液。 ${ }^{[4]}$ 在此基础上, 逐步建立 以校内专业设计教师、文化旅游专业教师、乡村振兴 设计项目企业设计师、乡村规划改造政策研究导师共 同培养人才的特色教师队伍。

\subsection{4 转变传统校企合作方式, 研发新型高职} 设计人才实习、择业、就业方案

将校企合作项目、设计实习项目从中心城市拓展 到广大乡村, 院校与设计企业共同推进优质乡村振兴 设计实战项目，乡村与院校共乡村建 “设计师工作站”, 引导将学生择业目标从城市转向乡村, 拓宽高职艺术 设计人才实习、择业、就业渠道, 推广设计人才参与 乡村振兴的设计成果, 促使更多高职艺术设计人才将 设计才能贡献到乡村振兴的宏图中来。

\section{2.5 建构以乡村振兴实战设计项目为主导,} 高职设计人才考评、评价、学分认定方式

转变以专业课程成绩认定为核心的考评机制, 将 学生参与乡村设计项目类目次数、设计成果经济效能 转化、设计项目实用评价纳入到人才的考评、评价中。

\section{7. 总结}

随着国家乡村振兴战略的持续推进, 专业设计人 才服务乡村振兴的成效性日益凸显。积极展开高职设 计专业人才培养模式的改革, 逐步建构符合乡村振兴 需求符合时代需要的人才培养方案迫在眉眏。 ${ }^{[5]}$ 面对 现阶段高职设计教育存在的若干问题, 需积极推动教
学模式改革, 逐步推进高职设计专业课程体系架构革 新, 探索高职艺术设计教师队伍的重构方式, 转变传 统校企合作方式，研发新型高职技术设计人才实习、 择业、就业方案, 建设以乡村振兴实战设计项目为主 导高职艺术设计人才考评、评价、学分认定方式等具 体实施内容。厘清高职艺术设计人才对接乡村振兴战 略的具体工作岗位与设计工作职责, 明确乡村产业振 兴、文化振兴、文旅融合振兴与艺术设计人才间的对 应关系, 构建起高职院校在乡村振兴视域下设计类人 才培养的范式。通过完善高职设计类专业人才培养模 式，进一步提高设计类专业教育质量，培养符合国 家战略需求、为区域乡村经济发展做出贡献的专业设 计人才, 为我国全面实现乡村振兴发展战略提供强有 力的专业人才保障。

\section{REFERENCES}

[1] Wang, S.Y. (2014) China Sustainable Residential Architecture and Design, Southeast Higher University Education Press, Nanjing.

[2] Gu,B.G., Cui,Y.P.(2019) New Era China's Rural Revitalization Strategy Series, Zhongyuan Farmers Publishing Press, ZhengZhou.

[3] Deng, A.M., Lu.J.Y. (2020) Study On Sustainable Development Of Rural Tourism In Cultural And Tourism Integration, China Financial and Economic Press, Beijing.

[4] Wang, B.S. (2018) Regional Culture And Rural Revitalization Design,Hunan University Press, ChangSha.

[5] Anuode Beilinye. (2013) Art And Intervention Of New Century Aesthetic Translation Series [M] ,Beijing Commercial Press, Beijing. 